recurrent acute otitis media, may help to identify a subgroup of children prone to effusions who require closer follow up. ${ }^{10}$

General practitioners are well placed to diagnose effusion and carry out the necessary surveillance. Microtympanometry, a sensitive method of diagnosing effusions of the middle ear, could help them in this. ${ }^{11}$ Doctors should be able to reassure the parents of most affected children that the effusions will resolve without any further action or adverse sequelae.

RUUT A DE MELKER

Chairman,

Department of General Practice,

University of Utrecht,

3511 ZC Utrecht, Netherlands
The treatment of persistent glue ear in children. Effective Health Care 1992; No 4

Robinson R. Less surgery for glue ear, says bulletin. $B M \mathcal{F} 1992 ; 305 ; 1454-5$.

Haggard $M$, Hughes $\mathrm{G}$. Screening children's hearing. A review of the literature and the implications of otitis media. London: HMSO, 1991.

Chalmers DC, Stewart I, Silva P, Mulvena A. Otitis media with effusion in children-the Dunedin sindy. London: MacKeith Press, 1989.

Paradise J. Otitis media during early life: how hazardous to development? Pediarrics 1981,68: 869-73.

6 Schilder AGM, Zielhuis GA, van den Broek P. De lange termign effecten van otitis media met effusie. Nigmegen: Katholieke Universiteit, Nimegen, 1991.

7 Gates GA, Cooper JC, Avery A, Prihoda TJ. Chronic secretory otitis media: effects of surgical management. Ann Otol Rhinol Laryngol 1989;89(suppl 138): 1-32.

8 Mandel EM, Rockette HE, Bluestone ChD, Paradise JL, Nozza RJ. Efficacy of amoxycillin with or without decongestant-antihistamine for otitis media with effusion in children. $N$ Engl $9 \mathrm{Med}$ 1987;316:432-7.

9 Thomsen J, Sederberg-Olsen J, Balle V, Vejlsgaard R, Stangerup SE, Bundesson G. Antibiotic treatment of children with secretory otitis media. Arch Otolaryngol Head Neck Surg 1989;115: 447-51.

10 Appelman CLM, Claessen JQPJ. Recurrent acute otitis media [dissertation]. Utrecht: University of Utrecht, 1992.

11 De Melker RA. Diagnostic value of microtympanometry in primary care. BMf 1992;304:96-7.

\title{
Academic medicine: plenty of room at the top
}

\section{Too many barriers to getting well trained}

Contrary to conventional wisdom, there is a shortage of doctors to fill senior research posts. "High quality clinical researchers are like gold dust," said Diana Dunstan of the Medical Research Council at a meeting on opportunities in clinical research held at the Royal College of Physicians just before Christmas. The council has difficulty filling its senior training fellowships and professorships, and so, other speakers confirmed, do the major medical charities. "If you want a career in research and you are able then you have absolutely no need to worry," Peter Lachmann, president of the Royal College of Pathologists, told the young doctors at the conference. "Clinical research," he said, "is a shortage specialty." A great many young doctors do enter research, but few are reaching the stage where they are qualified for the senior jobs. What is the block?

The first problem is that many young doctors do not get an adequate training. Speakers like Sir David Weatherall from Oxford and Keith Peters from Cambridge all agreed that a proper training means at least three years doing nothing but research. Furthermore, the training must be in a good centre and must be well supervised. In effect this means doing a PhD rather than an $M D$, and the message from the conference was that an MD is a devalued degree. Yet the reality for most doctors is that their research time is undermined by clinical commitments ("Research can wait but patients can't") and training and supervision are poor. "Too much time is spent on ill considered, ill conceived research," said Mike Peckham, director of research and development in the NHS.

Another problem is the need to get accredited. The several presidents of colleges present at the meeting kept insisting that "accreditation is dead" and not a problem: there is plenty of flexibility in the system, they said. Yet it didn't feel that way to the young doctors. "We are made to do things that are a waste of time in order to get accredited," said one. "The colleges want their pound of flesh," said another. The only spontaneous applause during the day was for Sir Christopher Booth, who said: "The colleges ought to realise that accreditation is for NHS consultants working alone and that a quite different form of accreditation is needed for research academics working in teams."

The deeper problem for doctors going into research is the antiscience culture that is more important in medicine than many would care to admit. For example, Professor Peckham quoted a director of public health who said that people did not ask about research evidence even when making difficult decisions. Doctors who want to devote much of their time to research are undervalued. Inevitably they have more restricted clinical skills than those who practise full time. Particularly in the macho world of surgery, the researchers' clinical limitations may raise eyebrows while their abilities in molecular biology are more likely to be seen as a threat than an achievement. (An irony of the conference was that not one shred of evidence was produced for the central assertion that three years' full time training in research was essential.)

Money is another factor diverting doctors from a career in research, although it was not discussed much at the conference. The sad truth is that doctors who spend careers in research may forgo huge incomes from private practice. This is especially true in surgery and cardiology, two of the specialties that have the greatest difficulty in producing adequately trained academics.

The group who face the most difficulty getting adequately trained are women doctors, and they made their voices heard at the conference despite the organisers admitting with startling candour that they had not anticipated that this issue would arise. The women wanted more opportunities for part time training in research, but the male establishment was doubtful-arguing that "triple accreditation" as a clinician, scientist, and mother was too much. The women pointed out that many of the most able graduates were women and that it was shortsighted of the establishment simultaneously to be moaning about the lack of people at the top and disenfranchising half of medical graduates. Indeed, the one thing that spoilt this lively conference was the patronising references to women, district general hospitals, and general practice.

The conference illustrated why so few doctors manage to reach a position where they can apply for the senior fellowships and professorships, but answers were less forthcoming. The Medical Research Council is about to review its training structure, and the colleges clearly need to clarify the message on accreditation. But real developments may demand financial and cultural changes which may be difficult to achieve. My final message is to repeat that I think that Britain needs an organisation of researchers under 40 like those that exist in the United States and Australia. ${ }^{12}$ Such an organisation can campaign for better conditions for researchers, provide mutual support and advice, and talk up the importance of medical research with the public, schoolchildren, the government-and other doctors.

Editor, $B M \mathcal{F}$

RICHARD SMITH

Smith R. Science in Australia: alive, well, kicking, and growing. BMf 1991;302:840-2. 2 Smith R. Strangling the future. BMf 1991;302:977-8. 